\title{
Analgesic nephropathy in the United Kingdom: incidence, clinical features and pathogenesis
}

\author{
J RODNEY COVE-SMITH
}

From North Ormesby Hospital, Middlesbrough, Cleveland TS3 $6 \mathrm{HJ}$

Phenacetin came into use in 1887 , just 10 years after the first case of renal papillary necrosis was reported $^{12}$ but the association between the excessive use of phenacetin-containing analgesics and the development of renal damage was not recognised until $1953,{ }^{3}$ since when there has been gradual recognition that excessive analgesic consumption is a major cause of chronic renal disease in many parts of the world.

The initial emphasis on phenacetin has given way to the realisation that many analgesic mixtures are nephrotoxic. Such mixtures are readily available to the public and are widely advertised, not just for pain relief, but as tonics and general panaceas. Despite restrictions on the sale of phenacetin and its major metabolite paracetamol in several countries, abuse of analgesic mixtures has continued and there is no definite evidence that the incidence of analgesic nephropathy is declining.

Renal damage in analgesic nephropathy is due to a combination of renal papillary necrosis and chronic interstitial nephritis. In many cases the disease runs a rapidly progressive course with death from renal failure within a few years of the initial presentation.

This paper is based on a study carried out in Nottingham, and outlines the major features of analgesic nephropathy in the United Kingdom. The clinical features of analgesic nephropathy are now widely recognised yet many patients have already developed severe renal failure by the time the history of analgesic abuse is obtained. ${ }^{45}$ Unless the association with a high analgesic consumption is recognised, the renal damage is often attributed to bacterial infection and the condition labelled "pyelonephritis." Several studies have shown, however, that bacterial urinary tract infection in the adult rarely leads to end-stage renal failure, ${ }^{56}$ and Heptinstall has emphasised that the small, scarred kidney often labelled "chronic pyelonephritis" is the end result of many different pathological processes; in many cases the original disease cannot be determined.?

Early diagnosis of analgesic nephropathy is important since complete withdrawal of analgesics before significant renal damage has occurred will result in improvement in renal function.

\section{Renal papillary necrosis}

Necrosis of the renal papillae was first reported by von Friedreich in 1877 in the kidneys of an elderly man with hydronephrosis secondary to prostatic hypertrophy. He postulated that the increased pressure in the renal pelvis led to flattening of the papilla and kinking of the papillary vessels, resulting in local ischaemia. ${ }^{2}$ One hundred years later the exact mechanisms responsible for renal papillary necrosis remain uncertain, but local ischaemia is believed to play an important role.

Most of the early cases of papillary necrosis were described in patients with urinary tract obstruction or diabetes mellitus, but in the 1950s a "new" form of renal papillary necrosis was reported from Switzerland and Sweden ${ }^{8}$ associated with the consumption of large quantities of phenacetin-containing analgesics.

First reports of "phenacetin nephropathy" in the United Kingdom came in 1964. Sanerkin and Weaver ${ }^{9}$ emphasised that the chronic interstitial nephritis of phenacetin abuse was essentially indistinguishable from chronic non-obstructive pyelonephritis, except for the presence of papillary necrosis, and that the apparent scarcity of the condition in the United Kingdom might reflect the failure of clinicians and pathologists to recognise it.

They suggested "that particular enquiry should always be made into phenacetin intake in all patients with chronic pyelonephritis and at necropsy special attention should be paid to the renal papillae."

In 1966 Dawborn et al. ${ }^{10}$ presented convincing evidence that renal papillary necrosis was the primary lesion with cortical changes occurring as a secondary event; these included tubular dilatation, interstitial nephritis and a decrease in the size of the kidneys. 
Between 1953 and 1970 there was a marked rise in the number of diagnosed cases of renal papillary necrosis, particularly in Scandinavia, Switzerland and Australia. This probably reflected both a true increase in incidence of the disease and increased awareness of it.

\section{INCIDENCE IN THE UNITED KINGDOM}

After the initial reports of analgesic nephropathy in Britain in 1964, several larger series were reported, mainly from Scotland. In 1970 Koutsaimanis and de Wardener, ${ }^{11}$ on the basis of 16 patients seen at one London hospital, estimated that the incidence of analgesic nephropathy in England and Wales would be around 500 new cases per year.

A survey of chronic renal disease in Nottingham in 1973 suggested that analgesic nephropathy might account for at least $10 \%$ of cases of chronic renal failure. ${ }^{12}$ This survey was subsequently extended to include all reported cases of renal disease seen at the two major Nottingham hospitals between 1970 and 1975. Information about the patients came from four sources:

(1) Patients referred to the nephrologists for investigation or treatment.

(2) Survey of chronic renal disease, 1973.

(3) Survey of case notes of patients with renal disease.

(4) Survey of all necropsies performed in the two hospitals 1970-5.

In all cases where analgesic nephropathy was suspected, or renal papillary necrosis was present, case notes and radiographs were carefully examined and the patient and relatives questioned about analgesic intake. The reasons for any excessive analgesic consumption were documented and changes in renal function correlated with the quantity of analgesics consumed. By the time the diagnosis was made, in all cases, more than 1 kilogram of analgesics had been taken and in the majority more than 2 kilograms-equivalent to 6 tablets a day for 5 years.

As part of the survey 20229 necropsy reports were examined for the presence of renal disease. The necropsy rate in the Nottingham hospitals was $65 \%$, which is higher than that reported in many other series. ${ }^{1314}$ Nevertheless the survey probably underestimated the true incidence of papillary necrosis, for in only about half of the necropsy reports was there evidence that the papillae had been examined.

Table 1 indicates the causes of renal papillary necrosis in the Nottingham survey. The incidence is similar to that in other series from Europe and the UK which ranges from $0 \cdot 16-1 \cdot 7 \%{ }^{1516}$ Gloor reported a significant increase in the incidence of papillary necrosis from $0.94 \%$ of all necropsies in $1939-50$ to
Table 1 Causes of renal papillary necrosis: necropsy study, Nottingham hospitals 1970-5

\begin{tabular}{ll}
\hline Total number of necropsies in survey & $\begin{array}{l}\text { No of necropsies } \\
20229\end{array}$ \\
\hline Renal papillary necrosis, total & $83(0 \cdot 41 \%)$ \\
unilateral & $10\}$ \\
bilateral & $73\}$ \\
Attributed to: & 30 \\
diabetes mellitus & 22 \\
obstruction & 20 \\
analgesic nephropathy & 7 \\
acute pyelonephritis & 4 \\
other & \\
\hline
\end{tabular}

$1.71 \%$ in 1951-62, which he attributed to an increase in cases of analgesic nephropathy. ${ }^{17}$ During the same period the incidence of papillary necrosis due to diabetes and urinary tract obstruction remained unchanged.

Tables 2 and 3 list the major necropsy series reporting renal papillary necrosis in various countries. The incidence in these countries differs largely as a result of the presence of analgesic nephropathy and can be related to the per capita consumption of analgesic preparations, estimated to be at least four times as high in Australia as in the United States or Great Britain. One necropsy series in Australia suggested an incidence of renal papillary necrosis as hig as $11 \%$ of women who lived in Brisbane; ${ }^{23}$ the sams authors claimed that one third of all deaths from renal disease were due to analgesic abuse. A similar study from Sydney showed that analgesic nephropathy accounted for $25 \%$ of patients with nonterminal renal failure during $1976 .{ }^{24}$

It is clear that this condition has now reached epidemic proportions in many parts of the world and the evidence from Nottingham suggests that in the UK analgesic nephropathy accounts for at least $12 \%$ of cases of chronic renal failure. Unfortunately, although the condition is potentially curable, many patients still die before the association with analgesic ingestion is recognised. Unless a careful drug history is taken and the clinical features recognised the diagnosis will be missed.

\section{Clinical features of analgesic nephropathy}

Apart from the history of analgesic abuse there may be little to distinguish the clinical picture from other forms of renal disease. For this reason the history $\widetilde{\sim}$ from any patient presenting with renal problems $\underset{\omega}{ }$ should include a careful enquiry into the intake of tablets, powders and medicines. Particular attention 0 should be paid to a history of headache, migraine or $\overparen{D}$ arthritis, and a list compiled of all medications, ? especially those bought "over-the-counter."

There are a number of features which should make 
Table 2 Incidence of renal papillary necrosis (RPN) in Europe, USA and UK necropsy series 1947-75

\begin{tabular}{|c|c|c|c|c|}
\hline Authors & Dates of survey & Country & No of necropsies & $\%$ incidence $R P N$ \\
\hline Heptinstall? & $1947-61$ & USA & 11000 & 0.23 \\
\hline Schourup ${ }^{18}$ & $1951-55$ & Denmark & 5000 & 1.05 \\
\hline Gloor 25 & $1955-64$ & Switzerland & 18810 & 1.0 \\
\hline & $1968-72$ & Switzerland & 9795 & $1 \cdot 0$ \\
\hline Davies et $a l^{15}$ & $1964-69$ & UK & 18866 & 0.16 \\
\hline Cove-Smith \& Knapp ${ }^{6}$ & $1970-75$ & UK & 20229 & 0.41 \\
\hline
\end{tabular}

Table 3 Estimated annual per capita consumption of phenacetin and incidence of analgesic nephropathy in different countries

\begin{tabular}{|c|c|c|c|}
\hline Country & Phenacetin consumption $\mathrm{g} / \mathrm{yr}$ & $\begin{array}{l}\text { Analgesic nephropathy as a cause } \\
\text { of chronic renal failure }\end{array}$ & $\%$ incidence $R P N$ \\
\hline Australia & $40 \mathrm{~g}^{1}$ & $\begin{array}{l}30 \% \\
25 \%\end{array}$ & $\begin{array}{l}3.00-11.00 \text { (Brisbane) }^{23} \\
8.40 \text { (Sydney) }^{26}\end{array}$ \\
\hline Denmark & $25 \mathrm{~g}^{18}$ & - & $1.05^{18}$ \\
\hline Switzerland & $23 \mathrm{~g}^{19}$ & - & $1 \cdot 00^{25}$ \\
\hline South Africa & $12 \cdot 5 \mathrm{~g}^{20}$ & $20 \%$ & - \\
\hline Scotland & $12 \mathrm{~g}^{21}$ & $25 \cdot 5 \%$ & $\begin{array}{l}0 \cdot 60^{21} \\
0.54^{28}\end{array}$ \\
\hline England and Wales & $8 \mathrm{~g}^{11}$ & $12 \%$ & $0.41^{\circ}$ \\
\hline USA & $10 \mathrm{~g}^{22}$ & $7 \%$ & $0 \cdot 23^{7}$ \\
\hline Canada & $6-7 \mathrm{~g}^{22}$ & $5.5 \%$ & - \\
\hline
\end{tabular}

$\mathbf{R P N}=$ renal papillary necrosis.

Table 4 Clinical features of analgesic nephropathy in the UK

\begin{tabular}{ll}
\hline Women:Men $4: 1$ & Anaemia \\
Age $>30$ yr & Sterile pyuria \\
Excessive analgesic consumption & Recurrent urinary infections \\
Headaches & Uraemia \\
Premature ageing & Passage of papillae \\
Psychiatric disturbance & Haematuria \\
Dyspepsia & Renal colic \\
\hline
\end{tabular}

the clinician suspect analgesic abuse (see Table 4). The typical patient is a sallow, middle-aged housewife who complains of persistent headaches and recurrent ill health. Marital and psychiatric problems are common. Most patients readily admit taking tablets, but only careful questioning reveals the full extent of the "analgesic abuse." Many obtain a psychological "lift" from the tablets as well as pain relief, and intakes of $20-50$ tablets daily are not uncommon.

Most patients present with symptoms and signs of chronic renal failure, but a few present acutely with renal colic, urinary infections or dyspepsia. Rapid deterioration in renal function may follow an episode of dehydration, or ureteric obstruction due to the separation of a calcified papilla or of papillary fragments.

Clinical examination is often unhelpful. Anaemia may be more severe than expected from the degree of renal failure; this has been attributed to chronic gastrointestinal bleeding due to a high salicylate intake. Hypertension is uncommon and proteinuria is moderate or absent in the early stages.

Examination of the urine typically reveals numerous leucocytes with or without bacterial infection. A persistent sterile pyuria should alert the clinician to the possibility of analgesic nephropathy, but many patients also suffer from recurrent urinary tract infections. Occasionally the passage of debris may indicate shedding of a papilla; in this case the urine should be strained and any tissue sent for histological examination.

Haematuria may indicate active papillary necrosis, but can also herald the development of a transitional carcinoma of the renal pelvis, which occurs in about $10 \%$ of cases of analgesic nephropathy. ${ }^{30}$ Regular cytological examination of the urine may help in the early detection of these tumours. ${ }^{31}$

A very useful technique both for diagnosis and for following patients with analgesic nephropathy is to examine a sample of urine for salicylates and paracetamol: one method involves saturating the urine sample with salt, after which the urine is extracted with ether and scanned under ultraviolet light.32 "Phenistix" (Ames) can be used as a simple screening test and will detect salicylates in the urine for up to 48 hours after ingestion. ${ }^{33}$

Radiological appearances reflect the pathological changes. In the early stages intravenous urography may be normal. Typical $x$-ray changes of papillary 
necrosis are seen in only $20-30 \%$ of cases. The commonest finding is reduction in size of both kidneys with irregularity of the outline due to shallow scars, which may often be misinterpreted as "chronic pyelonephritis."

Renal biopsy is generally unhelpful since it merely shows interstitial nephritis without indicating the cause. Lee et al. ${ }^{34}$ suggested that demonstration of a lipofuscin pigment in the tubules should arouse suspicion of analgesic abuse but this occurs in other conditions and an accurate drug history should already have alerted the clinician to the possibility of analgesic damage.

Management consists of total avoidance of analgesics, careful long-term supervision of hypertension, salt and water balance and urinary tract infections, and a constant awareness and early detection of serious complications such as urinary tract obstruction and transitional cell carcinoma. Evidence of cessation of analgesic abuse should be obtained by routine screening of urine for salicylates and paracetamol.

\section{Analgesic nephropathy and "chronic pyelonephritis"}

The chief difficulty in diagnosing analgesic nephropathy has been to distinguish it from chronic pyelonephritis. For many years the term "chronic pyelonephritis" was applied by pathologists and radiologists to any small scarred kidney, particularly if inflammatory cells could be demonstrated in the renal parenchyma. It is now realised that scarring and contraction of the kidney, with interstitial inflammation and fibrosis, are the end result of many different processes including damage due to ischaemia and drugs. ${ }^{7}$ The term "chronic pyelonephritis" should probably be reserved for cases in which renal damage can be attributed to bacterial invasion of the renal tissue. Careful examination of cases of chronic nonobstructive pyelonephritis in Britain suggests that there are only two major causes:

(1) Damage associated with vesico-ureteric reflux during childhood or pregnancy (reflux nephropathy).

(2) Analgesic nephropathy.

According to the proceedings of the European Dialysis and Transplant Association (1970-77), chronic pyelonephritis accounts for about $20 \%$ of patients referred to dialysis/transplantation programmes. ${ }^{35}$ Analgesic nephropathy appeared as a separate cause of renal failure for the first time in 1975. Before this it had been included in "druginduced pyelonephritis," accounting for some $3 \%$ of cases. The results of the Nottingham necropsy study suggest that renal failure due to chronic pyelone- phritis is a relatively uncommon cause of death in patients under 65 years of age, and that analgesic nephropathy may have been seriously underdiagnosed, ${ }^{36}$ because of the lack of a careful enquiry into analgesic consumption and the problem of establishing the presence of papillary necrosis by intravenous urography.

The importance of making a distinction between analgesic nephropathy and chronic pyelonephritis has been emphasised by Gower. ${ }^{37}$ In a series of patients with radiological evidence of pyelonephritis he observed that deterioration in renal function occurred more rapidly in the group taking analgesics. Most of the patients with papillary necrosis in his series had a history of analgesic abuse and their survival rate was $56 \%$ at 10 years, compared with $86 \%$ for those without papillary necrosis. In the Nottingham series the survival rate was only $44 \%$ at 5 years, reflecting the poor renal function of most patients at presentation. The prognosis was especially poor if the serum creatinine found at the time of diagnosis was greater than $400 \mu \mathrm{mol} / \mathrm{l}$, and the mortality rate could be related both to the degree of renal failure and the estimated total consumption of analgesics.

\section{Pathogenesis of analgesic nephropathy}

Burry refers to three stages of papillary necrosis: $3 \times$ 을 namely, early, intermediate and total.

In the early stage only the papillary tip appears to be affected, with yellow coloration and some pale streaking of the pyramid; the cortex is normal.

In the intermediate stage the papillae are intact but shrunken and pale with radial streaks marking the upper zone of degeneration. The cortex is often coarsely scarred but of normal thickness.

The group with total necrosis shows a range of changes. In the most severely affected kidneys the cortical surface is slightly irregular with raised areas corresponding to the "renal columns". The kidney is often reduced in size, with scars overlying necrotic papillae. The papillae are brown and withered, sometimes remaining in situ, sometimes separated or absent altogether. Calcification may be present in the pyramids.

On microscopy, the necrotic areas are structure- $\widetilde{N}$ less and often lack the clear line of demarcation with a zone of leucocytes which is usually seen in the acute lesion associated with diabetes or obstruction.

Cortical changes in total papillary necrosis include atrophy and loss of the convoluted tubules with increased interstitial fibrosis and variable numbers of chronic inflammatory cells. The glomeruli are usually spared.

The absence of cortical changes in the early stages 
of papillary necrosis and the sparing of the columns of Bertin indicate that papillary necrosis is the primary lesion with cortical damage occurring as a secondary event. Burry considers that this sequence of changes is best explained by a direct toxic effect on the tubules but others suggest that interference with the papillary blood supply is the primary event. ${ }^{39}$ There is evidence to support both theories, but so far the agent responsible for the damage has not been identified. The early emphasis on phenacetin may have been premature; it was a common constituent of many widely used analgesic preparations, together with aspirin, caffeine, codeine and phenazone, but early attempts to produce papillary necrosis in animals with phenacetin alone were unsuccessful. However, medullary damage was later induced by massive doses. ${ }^{40}$ In rats papillary necrosis is more readily and predictably induced by aspirin but many studies have now demonstrated that mixtures of aspirin and phenacetin are more nephrotoxic than either drug alone and the lesion produced by such mixtures is identical with that seen in man. ${ }^{16}$

The difficulty of establishing the substance or substances responsible for papillary necrosis in man can be largely attributed to species differences. Experiments in animals cannot readily be extrapolated to man and there are variations even between different strains of rat. In man phenacetin is rapidly and almost totally metabolised to paracetamol. A number of other metabolites have been identified but little is known about their renal toxicity. Bluemle and Goldberg ${ }^{41}$ showed that paracetamol is concentrated in the renal medulla and papilla with tissue:plasma ratios similar to those achieved for urea; salicylates on the other hand are distributed evenly throughout the kidney although concentrations are considerably higher than in the plasma. ${ }^{41}$ Recent studies suggest that phenacetin or its metabolities or both cause direct oxidative damage in the renal papillary cells. This action may be potentiated by salicylates, which inhibit glucose-6phosphate dehydrogenase (G6PD), an enzyme involved in the defence of tissues against oxidative damage. ${ }^{42}$

Electron microscopy studies by Molland have shown damage to medullary interstitial cells in rats following chronic ingestion of aspirin, and it is suggested that this drug may produce medullary ischaemia through inhibition of prostaglandin synthesis. ${ }^{43}$ Prostaglandin $\mathrm{PGE}_{2}$, which is synthesised in the renal medulla, is believed to act locally as a vasodilating hormone.44 Thus, salicylates may potentiate the effect of the toxic metabolites of phenacetin or paracetamol in the renal papilla. In animals this damage is increased by dehydration, which may also play an important part in man.

Aspirin or paracetamol alone have only been incriminated in a few cases of analgesic nephropathy, since most patients take analgesic mixtures. Chronic ingestion of paracetamol alone appears to have few harmful effects on the kidney, ${ }^{45}$ and despite the vast quantities of aspirin consumed throughout the world only a handful of cases can be attributed to its use. A study of patients taking large doses of aspirin for rheumatoid arthritis showed no increased incidence of papillary necrosis. ${ }^{46}$ Other drugs which inhibit prostaglandin synthesis, such as indomethacin and phenylbutazone, have been incriminated in a few cases of analgesic nephropathy. 47

It is now accepted that in the majority of cases analgesic nephropathy results from the excessive consumption of analgesic mixtures, usually containing aspirin with either phenacetin or paracetamol. The synergism between aspirin and phenacetin may be the result of some complex metabolic interaction, but it seems likely that the inhibition of prostaglandin synthetase in the renal medulla by aspirin causes relative ischaemia and that, particularly in the presence of dehydration, toxic metabolites of phenacetin, which probably include paracetamol, are concentrated in the renal papilla and damage the ischaemic tissue.

Phenacetin has recently been replaced by paracetamol in many analgesic mixtures available "overthe-counter." It is too early to say whether this will lead to a reduction in the incidence of analgesic nephropathy.

In summary, analgesic abuse remains an important cause of renal damage which is still commonly missed. The diagnosis depends on a high index of suspicion and a careful search for the features of analgesic nephropathy. Early diagnosis is important since cessation of analgesic intake may result in improvement in renal function.

\section{References}

${ }^{1}$ Ross P. APC as a cause of renal disease. Med J Aust 1962; 2:539-42.

2 von Friedreich N. Über Nekrose der Nieren papillen bei Hydronephrose. Virchows Archiv 1877;69:308.

${ }^{3}$ Spühler O, Zollinger HU. Die chronisch-interstitielle Nephritis. Zeit klin Med 1953;151:1-50.

4 Murray T, Goldberg M. Chronic interstitial nephritis: etiologic factors. Ann Intern Med 1975;82:453-9.

${ }^{5}$ Cove-Smith JR, Knapp MS. Analgesic nephropathy: an important cause of chronic renal failure. Quart $J$ Med 1978;47:49-69.

6 Bailey RR. The relationship of vesico-ureteric reflux to urinary tract infection and chronic pyelonephritisreflux nephropathy. Clin Nephrol 1973;1:132-41.

${ }^{7}$ Heptinstall RH. Pathology of the kidney. 2nd ed. Bosto Little, Brown and Company, 1974.

${ }^{8}$ Lindvall N. Renal papillary necrosis. Acta Radiol 1960 suppl 192:1-153. 
${ }^{9}$ Sanerkin NG, Weaver CM. Chronic phenacetin nephropathy. Br Med J $1964 ;$; :288.

${ }^{10}$ Dawborn JK, Fairley KF, Kincaid-Smith P, King WE. The association of peptic ulceration, chronic renal disease and analgesic abuse. Quart J Med 1966;35:69-83.

${ }^{11}$ Koutsaimanis KG, de Wardener HE. Phenacetin nephropathy with particular reference to the effect of surgery. Br Med J 1970;iv:131-4.

${ }^{12}$ Cove-Smith JR, Knapp MS. Sodium handling in analgesic nephropathy. Lancet 1973 ;ii:70-2.

13 Jacobs LA, Morris JG. Renal papillary necrosis and abuse of phenacetin. Med J Aust 1962;2:531-8.

${ }^{14}$ Cameron HM, McGoogan E, Watson H. Necropsy: a yardstick for clinical diagnoses. Br Med J 1980;281:9858.

${ }^{15}$ Davies DJ, Kennedy A, Roberts C. The aetiology of renal medullary necrosis: a survey of adult cases in Liverpool. $J$ Pathol Bacteriol 1970;100:257-68.

${ }^{16}$ Nanra RS, Kincaid-Smith P. Chronic effects of analgesics on the kidney. In: Edwards KDG. Drugs affecting kidney function and metabolism. Prog Biochem Pharmacol Vol 7. Basel: Karger, 1972: p. 285-323.

17 Gloor FJ. Some morphological features of chronic interstitial nephritis (chronic pyelonephritis) in patients with analgesic abuse. In: Kass EH. Progress in pyelonephritis. Philadelphia: Davis, 1965: p. 287-96.

${ }^{18}$ Schourup K. Necrosis of the renal papillae. Acta Pathol Microbiol Scand 1957;41:462-78.

19 Pletscher A. Über die Toxikologie des Phenacetin. Bulletin der schweizerischen Akademie der medizinischen Wissenschafen 1958;14:100.

${ }^{20}$ Levin NW, Rubenstein AH, Abrahams C, Jordaan JC, Posel MM. Phenacetin nephritis, interstitial nephritis and necrotising papillitis associated with chronic ingestion of phenacetin. $S$ Afr Med J 1962;36:555-9.

${ }^{21}$ Boyd DHA. The use and abuse of phenacetin. Scott Med J 1964;9:423-6.

22 Gault MH, Rudwal TC, Engles WD, Dossetor JB. Syndrome associated with the abuse of analgesics. Ann Intern Med 1968;68:906-25.

${ }^{23}$ Burry AF, Axelsen RA, Trolove P. Analgesic nephropathy: its present contribution to the renal mortality and morbidity profile. Med J Aust 1974;1:31-6.

${ }^{24}$ Stewart JH. Analgesic abuse and renal failure in Australasia. Kidney Int 1978;13:72-8.

${ }^{25}$ Gloor FJ. Changing concepts in pathogenesis and morphology of analgesic nephropathy as seen in Europe. Kidney Int 1978;13:27-33.

${ }^{26}$ Furman KI, Galasko GTF, Meyers AM, Rabkin R. Posttransplantation analgesic dependence in patients who formerly suffered from analgesic nephropathy. Clin Nephrol 1976;5:54-6.

27 Murray RM. Genesis of analgesic nephropathy in the United Kingdom. Kidney Int 1978;13:50-7.

${ }^{28}$ Cochran AJ, Lawson DH, Linton AL. Renal papillary necrosis following phenacetin excess. Scott Med J 1967; 12:246-50.

${ }^{29}$ Shimizu A. Incidence of terminal renal failure and facilities for its management. Ontario Medical Review May 1972.

30 Taylor JS. Carcinoma of the urinary tract and analgesic abuse. Med J Aust 1972;1:407-9.

31 Jackson B, Kirkland JA, Lawrence JR, Narayan AS, Brown HE, Mills LR. Urine cytology findings in analgesic nephropathy. J Urol 1978;120:145-7.

${ }^{32}$ Dordoni B, Willson RA. Thompson RPH, Williams R. Reduction of absorption of paracetamol by activated charcoal and cholestyramine: a possible therapeutic measure. Br. Med J 1973; ii : 86-7.

${ }^{33}$ Duggan JM. The Phenistix test in the detection of analgesic abuse. Med J Aust 1972;1:659.

${ }^{34}$ Lee HA, Davidson AR, Burston J. Analgesic nephropathy in Wessex: a clinico-pathological survey. Clin Ncphrol 1974;2:197-207.

35 Proceedings of the European Dialysis and Transplant Association. Vols VII-XV. Tunbridge Wells: Pitman, 1970-1977.

${ }^{36}$ Cove-Smith JR. Analgesic nephropathy. MD Thesis, Cambridge University, 1979.

37 Gower PE. A prospective study of patients with radiological pyelonephritis, papillary necrosis and obstructive atrophy. Quart J Med 1976;45:315-49.

${ }^{38}$ Burry AF. The evolution of analgesic nephropathy. Nephron 1967;5:185-201.

${ }^{39}$ Nanra RS, Chirawong P, Kincaid-Smith P. Medullary ischaemia in experimental analgesic nephropathy-the pathogenesis of renal papillary necrosis. Aust NZ J Med $1973 ; 3: 580-6$.

10 Fordham C, Huffines WD, Welt LG. Phenacetin-induced renal lesions in the rat. In: Kass EH. Progress in pyelonephritis. Philadelphia: Davis, 1965: 325-31.

11 Bluemle LW, Goldberg M. Renal accumulation of sad cylate and phenacetin: possible mechanisms in th nephropathy of analgesic abuse. J Clin Invest 1968;406 2507-14.

${ }^{42}$ Murray TG, Goldberg M. Analgesic-associated nephropathy in the USA: Epidemiologic, clinical and pathogenetic features. Kidney Int 1978;13:64-71.

${ }^{43}$ Molland EA. Experimental renal papillary necrosis. Kidne Int 1978;13:5-14.

44 Itskovitz HD, Stemper J, Pacholczyk D, McGiff JC. Renal prostaglandins: determinants of intrarenal distribution of blood flow in the dog. Clin Sci Mol Med $1973 ; 45$, suppl $1: 321 \mathrm{~s}-4 \mathrm{~s}$.

${ }^{45}$ Edwards OM, Edwards P, Huskisson EC, Taylor RT Paracetamol and renal damage. Br Med J 1971;ii:87.

${ }^{46}$ New Zealand Rheumatism Association Study. Aspirin and the kidney. Br Med J 1974;i:593-6.

4 Krishnaswamy S, Nanra RS. "Phenacetin" nephropathy without phenacetin. Aust NZJ Med 1976;6:88.

Requests for reprints to: Dr JR Cove-Smith, Consultant Nephrologist, North Ormesby Hospital, Middlesbrough, Cleveland TS3 6HJ, England. 